\title{
Postprandial serum folic acid response to multiple doses of folic acid in fortified bread
}

\author{
Mary R. Sweeney ${ }^{1,2}$, Joseph McPartlin ${ }^{1}$, Donald G. Weir ${ }^{1}$, Leslie Daly ${ }^{2}$ and John M. Scott ${ }^{3}$ \\ ${ }^{1}$ Department of Clinical Medicine, University of Dublin, Trinity College, Dublin, Ireland \\ ${ }^{2}$ Department of Public Health Medicine and Epidemiology, University College Dublin, Earlsfort Terrace, Dublin 2, Ireland \\ ${ }^{3}$ Department of Biochemistry, University of Dublin, Trinity College, Dublin, Ireland
}

(Received 25 January 2005 - Revised 31 August 2005 - Accepted 11 November 2005)

\begin{abstract}
The benefit of the introduction of mandatory folic acid fortification of all flour products in the USA in 1998 has been amply demonstrated in a reduction of neural tube defect births. Doubt has been cast on the actual level of fortification and recent calculations have shown that the level of folic acid fortification is likely to have been over twice the amount mandated. The implication of this is that a greater proportion of the population are likely to have consumed folic acid at $>1 \mathrm{mg} / \mathrm{d}$, the Food and Drug Administration safe upper level of intake. Using the criteria of appearance of synthetic folic acid in serum, the objective of this pilot study was to investigate the consequences of consumption of baked bread preparations containing $1 \mathrm{mg}$ folic acid. Four healthy adult volunteers undertook each dosing schedule 2 weeks apart. This consisted of a single dose of $1000 \mu \mathrm{g}$, two doses of $500 \mu \mathrm{g}$, three doses of $333 \mu \mathrm{g}$, five doses of $200 \mu \mathrm{g}$ and, finally, ten doses of $100 \mu \mathrm{g}$. Serum was collected pre- and postprandially and analysed for synthetic folic acid by a combined HPLC-microbiological assay for folic acid. Folic acid appeared in all subjects at all test doses, with the effect more pronounced as the standard dose was administered in smaller amounts over the test period. Approaches to optimise folic acid intake in target populations as part of a universal fortification strategy should take into consideration the potential hazard of over-exposure in groups consuming high amounts of flour-based products.
\end{abstract}

Folic acid fortification: Synthetic folic acid in serum: Safe upper limit of intake

The normal circulating metabolite arising from natural food folate consumption is 5-methyltetrahydrofolate. In addition to this normal metabolite, unmetabolised folic acid arises in serum when the oral intake of synthetic folic acid saturates the normal intestinal absorptive capacity. This has been demonstrated at oral doses in the region of $200 \mu \mathrm{g}$ (Sweeney et al. 2003) and $266 \mu \mathrm{g}$ (Kelly et al. 1996). While the current level of fortification in the USA was calculated to achieve a mean increased intake of $100 \mu \mathrm{g} / \mathrm{d}$ (Food and Drug Administration (FDA), 1996), it has now been shown (Quinlivan \& Gregory, 2003) that the average increase in consumed folic acid ranges from 215 to $240 \mu \mathrm{g} / \mathrm{d}$. This implies that a far larger number of people are likely to consume folic acid at $>1 \mathrm{mg} / \mathrm{d}$, the upper limit recommended by government agencies internationally (FDA, 1996; National Academy of Sciences, 1998; Committee on Medical Aspects of Food and Nutrition Policy, 2000). While the FDA identified no clearly documented evidence of harm from over-consumption, conversely, it concluded that neither was there 'data available that established the safety of folic acid above $1 \mathrm{mg}$ per day' (FDA, 1996).

The FDA noted the potential risk for some population groups upon consumption of folic acid at levels higher than this. These included pregnant women, and persons on anti- epileptic and anti-folate medication. The FDA also noted the uncertainties regarding the effects of chronic exposure of children, whose requirements for folate are lower than those of adults, to increased intakes of folic acid. Other hypothetical concerns include the potential to promote cancer (Kim, 2004; Charles et al. 2004). However, the risk most extensively documented is a masking of anaemia in persons with vitamin B12 deficiency while irreversible neurological damage progresses (Savage \& Lindenbaum, 1995). Although the folate intake that produces masking is controversial, some argue that intakes $<1 \mathrm{mg}$ may cause this effect. Because of the likelihood of even greater consumption of higher doses of folic acid by larger numbers of people, we investigated the effects of $1 \mathrm{mg}$ folic acid in a variety of dosage schedules by assaying unmetabolised folic acid in serum. The pilot study was designed to reflect all possible daily eating patterns from a single large dose to multiple small doses.

\section{Methods}

In these studies we looked at the effects of consuming $1 \mathrm{mg}$ folic acid as a single dose, and as two, three, five and ten doses over $8 \mathrm{~h}$ periods. All studies were conducted 2 weeks

\footnotetext{
Abbreviation: FDA, Food and Drug Administration.

* Corresponding author: Dr Mary R. Sweeney, Department of Public Health Medicine and Epidemiology, University College Dublin, fax +35317167407 , email maryrose.sweeney@ucd.ie
} 
apart to prevent the likelihood that unmetabolised folic acid could be carried over in the circulation between studies. The fortified bread was prepared specially for each of the studies, with folic acid being added to the flour prior to baking to simulate fortification conditions.

\section{Recruitment, intervention and blood sampling}

Four healthy volunteers (one male and three females) were recruited from laboratory staff from whom written consent was obtained. All subject were between 20 and 30 years of age. All were free from hepatic or renal disease. None had been consumers of vitamin supplements or oral contraceptive pills. Subjects were advised of the various folic acid fortified food products available on the Irish market prior to commencement of the study and a list of alternative products available was issued. All subjects were found to be folate replete at initiation as determined by serum and erythrocyte folate measurements. On the morning of each study day all subjects were invited to the laboratory at 08.30 hours, having omitted folic acid-fortified food products for $24 \mathrm{~h}$ prior to sample collection. An intravenous cannula was inserted into each subject and a pre-prandial serum sample was collected from each for total folate and unmetabolised folic acid. The five pilot studies were carried out as follows.

\section{Regimen 1: $1 \mathrm{mg}$ folic acid consumed as a single dose in one} slice of bread

Subjects consumed one slice of bread, which was fortified

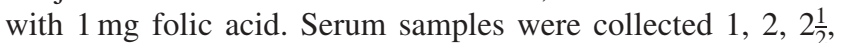
3 and $4 \mathrm{~h}$ postprandially.

\section{Regimen 2: $1 \mathrm{mg}$ folic acid consumed as two equal doses of $500 \mu \mathrm{g}$}

Subjects consumed one slice of bread fortified with $500 \mu \mathrm{g}$ folic acid. Serum samples were collected $1,2,2 \frac{1}{2}, 3$ and $4 \mathrm{~h}$ postprandially. A second slice of bread fortified with $500 \mu \mathrm{g}$ was then consumed by all subjects. Serum was collected 1 , $2,2 \frac{1}{2}, 3$ and $4 \mathrm{~h}$ postprandially.

\section{Regimen 3: $1 \mathrm{mg}$ folic acid consumed as three equal doses of $333 \mu \mathrm{g}$}

Subjects consumed one slice of bread fortified with $333 \mu \mathrm{g}$ folic acid. Serum samples were collected at 1,2 and $2 \frac{1}{2} \mathrm{~h}$ postprandially. This regimen of consumption and blood sampling was repeated twice until a total of $1 \mathrm{mg}$ had been consumed.

\section{Regimen 4: $1 \mathrm{mg}$ folic acid consumed as five equal doses of $200 \mu g$}

One slice of bread fortified with $200 \mu \mathrm{g}$ folic acid was consumed by each subject. A serum sample was collected from each subject 45 and 90 min later. This regimen was maintained until all five slices had been consumed.

\section{Regimen 5: $1 \mathrm{mg}$ folic acid consumed as ten equal doses of $100 \mu g$}

One slice of bread containing $100 \mu \mathrm{g}$ was administered to all subjects. Postprandial samples were collected $1 \mathrm{~h}$ later. This regimen of consumption and blood sampling was repeated nine times until a total of $1 \mathrm{mg}$ had been consumed.

\section{Laboratory analysis}

For total folate analysis whole blood was collected into nonheparinised serum separator tubes, allowed to clot at room temperature for $30 \mathrm{~min}$, then centrifuged at $2500 \mathrm{rpm}$ for $12 \mathrm{~min}$. Serum was collected and stored in $1.5 \mathrm{ml}$ plastic tubes at $-20^{\circ} \mathrm{C}$ until time of analysis.

For the erythrocyte folate analysis whole blood was collected into $5 \mathrm{ml}$ tubes lined with EDTA (anti-coagulant). Lysates of erythrocyte folates were prepared by the dilution of whole blood in a 1:10 dilution with freshly prepared 1\% ascorbic acid buffer. Samples were mixed thoroughly and placed at room temperature for $30 \mathrm{~min}$ to allow serum conjugase to convert folate polyglutamates released from the lysed erythrocytes to the assayable monoglutamate forms. The lysates were stored at $-20^{\circ} \mathrm{C}$ until times of analysis.

All samples were assayed for total serum and erythrocyte folate by Lactobacillus casei microbiological assay (Molloy \& Scott, 1997). All baseline samples were assayed within 1 week of collection. Analysis of samples for unmetabolised folic acid was carried out by HPLC-microbiological assay (Sweeney et al. 2003). Briefly explained, whole blood was collected into non-heparinised serum separator tubes, allowed to clot at room temperature for $30 \mathrm{~min}$, then centrifuged at $2500 \mathrm{rpm}$ for $12 \mathrm{~min}$. Aliquots $(0.5 \mathrm{ml})$ were collected into $1.5 \mathrm{ml}$ microfuge tubes. An internal radiolabelled standard $\left(\left[{ }^{3} \mathrm{H}\right]\right.$ folic acid $)$ was added. Samples were de-protenised with perchloric acid (60\%, v/v), vortexed, frozen, thawed and the supernatant was removed. $\mathrm{KOH}(6 \mathrm{M}, 50 \mu \mathrm{l})$ was added to the supernatant to bring the samples to $\mathrm{pH} 7 \cdot 0$. The unmetabolised folic acid was separated from all other folate forms in the sample by HPLC. Sample $(200 \mu \mathrm{l})$ was injected on to a $100 \times 8 \mathrm{~mm}$ C18 $\mu$ Bondapak ${ }^{\circledR}$; Waters Corporation, Milford, MA, USA. Fractions in the region of the known retention time for folic acid were collected and scintillation fluid was added to an aliquot of the sample to identify the radioactive peak. The remainder of the sample was then concentrated by solid-phase extraction and re-suspended in the minimum amount of liquid necessary for the microbiological assay. All samples were assayed in batch in triplicate and a mean value was calculated. Any samples not within the $5 \%$ standard deviation range were re-assayed.

\section{Statistical analysis}

ANOVA was performed for area under the curve data for serum folate and folic acid responses at each regimen. Data from each subject at each test dose are shown in Figs 1-5 as well as mean values in Fig. 6.

\section{Ethical considerations}

Subjects were recruited with ethical approval from the Joint Ethics Committee of Tallaght and St James's Hospitals. 
Subject 1

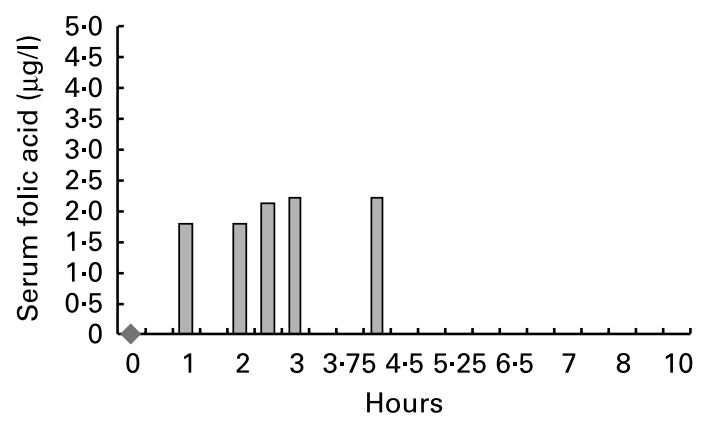

Subject 3

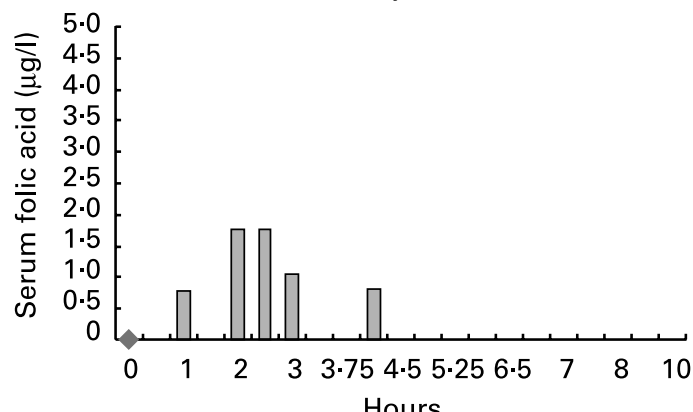

Subject 2

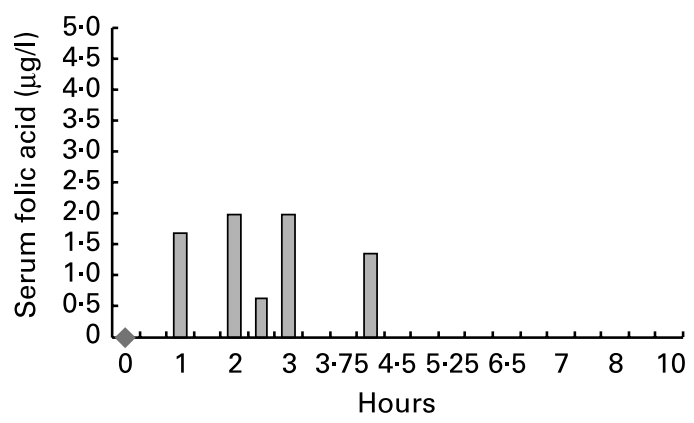

Subject 4

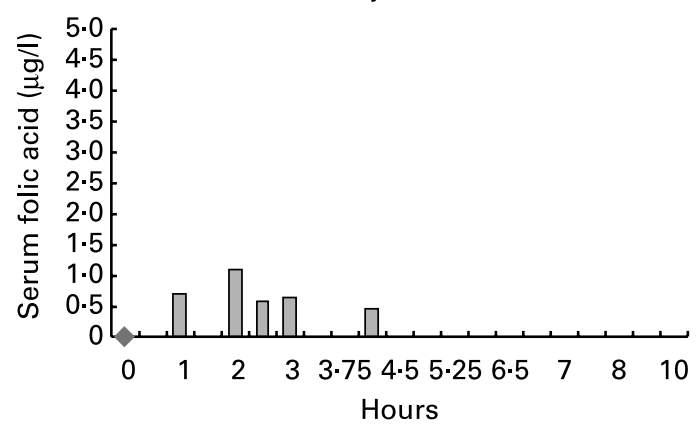

Fig. 1. Serum folic acid response in four subjects over a $4 \mathrm{~h}$ period after eating $1 \mathrm{mg}$ folic acid in a single slice of fortified bread. For details of procedures, see p. 146. $\diamond$ Time-point for bread consumption.
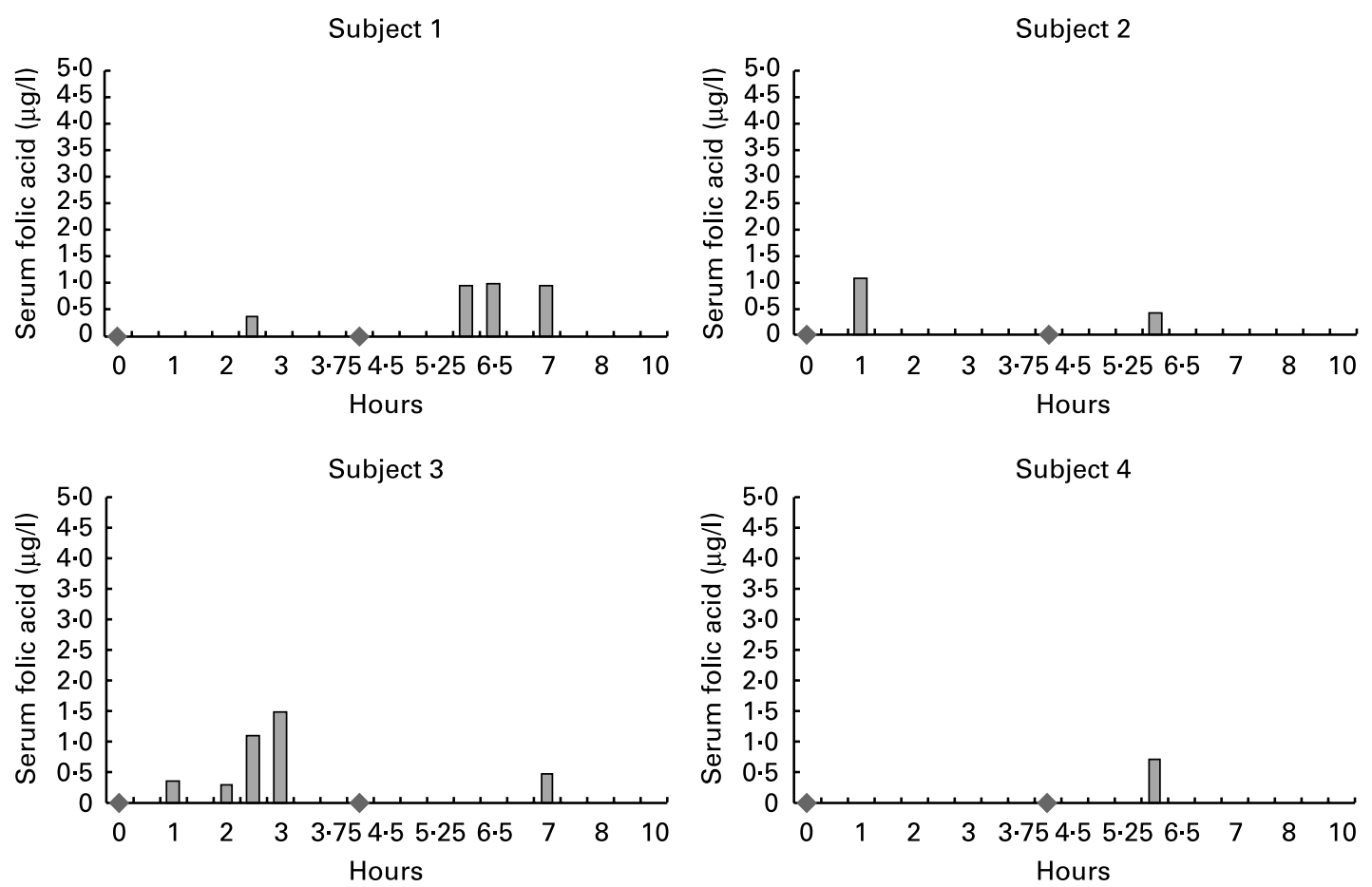

Fig. 2. Serum folic acid response in four subjects over an $8 \mathrm{~h}$ period after eating $1 \mathrm{mg}$ folic acid in two equal doses of $500 \mu \mathrm{g}$ in two slices of fortified bread served $4 \mathrm{~h}$ apart. For details of procedures, see p. 146. $\bullet$, Time-point for bread consumption.

\section{Results}

Table 1 illustrates baseline erythrocyte and serum folate concentrations. All subjects were within normal reference ranges.
Unmetabolised folic acid was not detected in the serum of any subject pre-prandially. Area under the curve analysis for serum folate increased significantly $(P=0 \cdot 0026)$, indicating compliance with the interventions. 

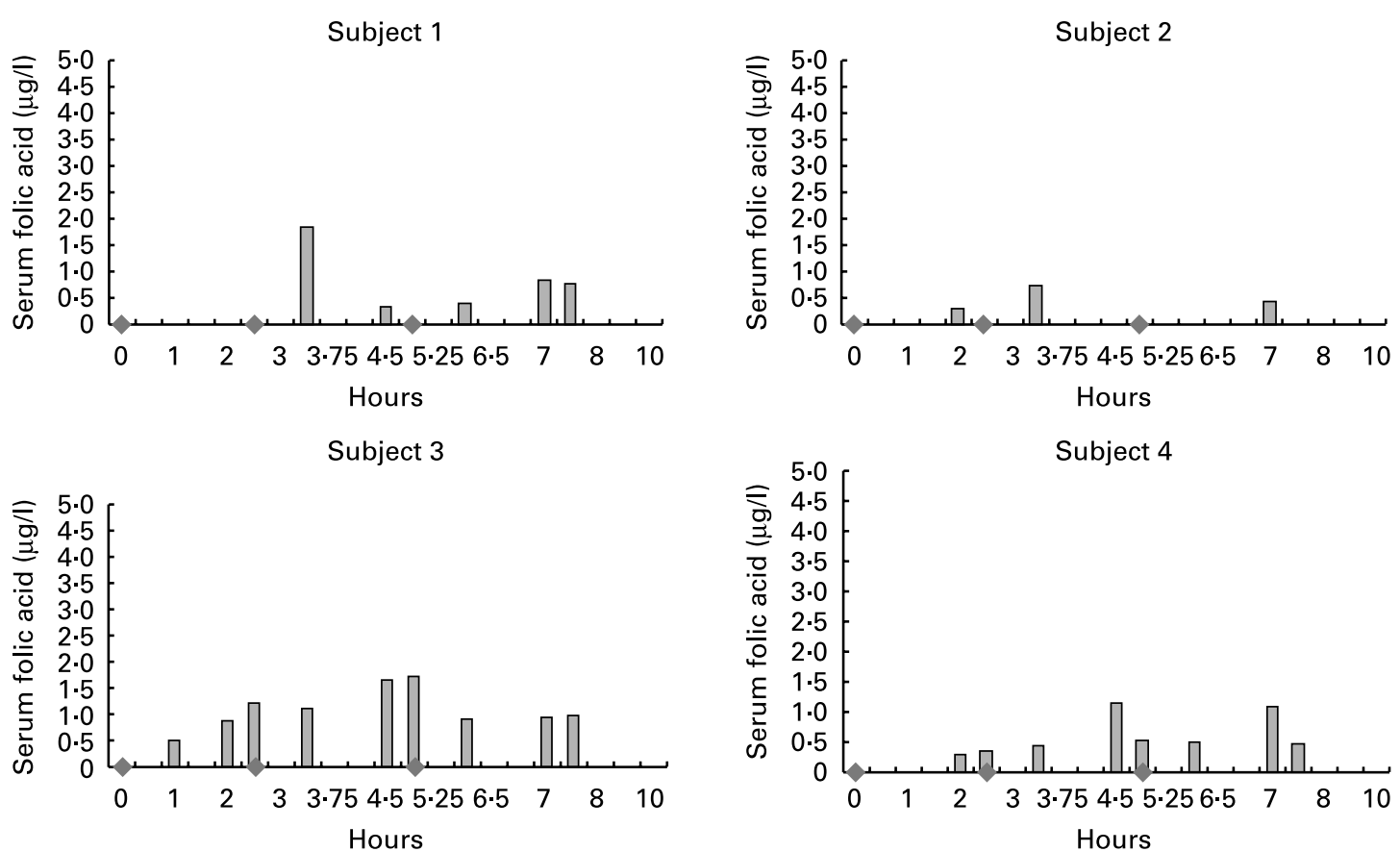

Fig. 3. Serum folic acid response in four subjects over an $8 \mathrm{~h}$ period after eating $1 \mathrm{mg}$ folic acid in three equal doses of $333 \mu \mathrm{g}$ in three slices of fortified bread served $2 \frac{1}{2} \mathrm{~h}$ apart. For details of procedures, see p. 146 . $\diamond$, Time-point for bread consumption.
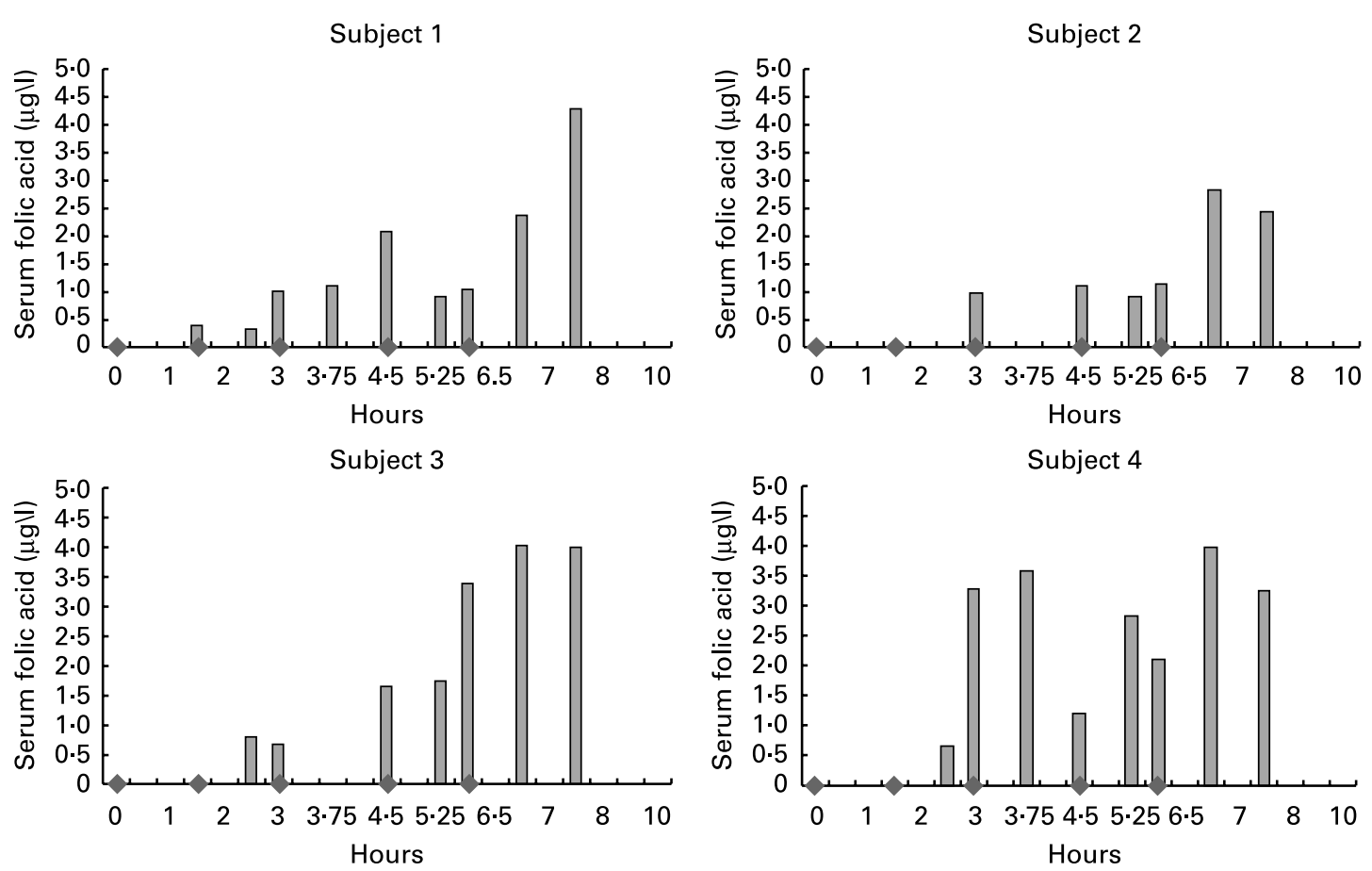

Fig. 4. Serum folic acid response in four subjects over an $8 \mathrm{~h}$ period after eating $1 \mathrm{mg}$ folic acid in four equal doses of $200 \mu \mathrm{g}$ in five slices of fortified bread served $90 \mathrm{~min}$ apart. For details of procedures, see p. 146 . Time-point for bread consumption.

Regimen 1: $1 \mathrm{mg}$ folic acid consumed as a single dose in one slice of bread

Unmetabolised folic acid was detected in the sera of all four

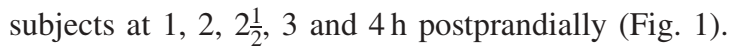

Regimen 2: $1 \mathrm{mg}$ folic acid consumed as two equal doses of $500 \mu \mathrm{g}$

Folic acid was detected in the sera of three out of four subjects after the first slice and in all four subjects after the second slice, each containing $500 \mu \mathrm{g}$ (Fig. 2). 

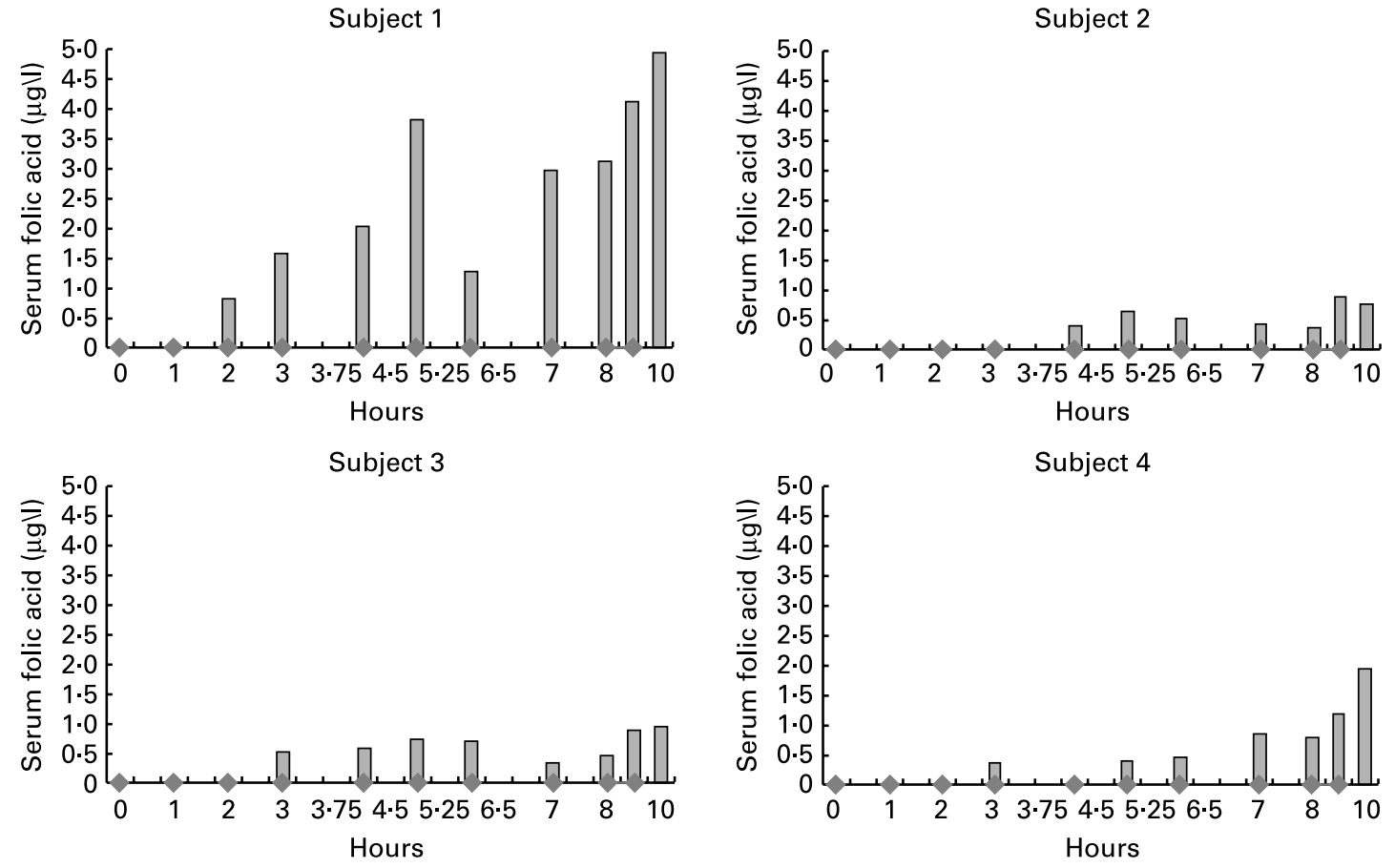

Fig. 5. Serum folic acid response in four subjects over a $10 \mathrm{~h}$ period after eating $1 \mathrm{mg}$ folic acid in four equal doses of $100 \mu \mathrm{g}$ in ten slices of fortified bread served $1 \mathrm{~h}$ apart. For details of procedures, see p. 146. $\diamond$, Time-point for bread consumption.

Regimen 3: $1 \mathrm{mg}$ folic acid consumed as three equal doses of $333 \mu g$

Folic acid was detected in three out of the four subjects after consumption of the first slice of bread containing $333 \mu \mathrm{g}$ folic acid (Fig. 3) and in all four subjects after the second and third slices of bread.

Regimen 4: $1 \mathrm{mg}$ folic acid consumed as five equal doses of $200 \mu g$

Unmetabolised folic acid was detected in the sera in one out of the four subjects after consumption of the first slice containing $200 \mu \mathrm{g}$ folic acid. Folic acid was detected in the sera of all four subjects after consumption of every subsequent slice. The results show that an apparent accumulative effect of serum folic acid occurred over the $8 \mathrm{~h}$ period with the highest level of folic acid being present after the fifth slice (Fig. 4).

\section{Regimen 5: $1 \mathrm{mg}$ folic acid consumed as ten equal doses of $100 \mu g$}

Folic acid was not present postprandially after the first slice of bread in any of the subjects. Subsequent slices administered, however, caused folic acid appearance in serum with again an apparent accumulative effect evident in all four subjects after repeated administration (Fig. 5).

\section{Discussion}

With the public health initiative of universal fortification it was accepted that by increasing the intake of folic acid the incidence of neural tube defects would be reduced, with the possible benefit of reduction in CHD and cancer as well
(Fairfield \& Fletcher, 2002). While this has indeed been the case for neural tube defect reduction (Honein et al. 2001), it remains to be determined whether or not increased consumption of folic acid is responsible for a reduction in diseases of later life. In issuing its guidelines for fortification, however, the FDA expressed caution in regard to over-consumption of the vitamin by setting a safe upper limit of $1 \mathrm{mg}$. The safety concerns were addressed recently by Kim (2004) who reviewed the effect of folate supplementation on cancer prevention and promotion in animal and human models to date. The author concluded that the potential for folic acid supplementation to promote the progression of colorectal adenomas is a legitimate public health concern that needs careful consideration. In addition a recent paper in the British Medical Journal (Charles et al. 2004) showed that the risk of maternal breast cancer was reported to be twice as great in women who took high doses of supplemental folic acid during pregnancy.

Unlike the natural form of the vitamin 5-methyltetrahydrofolate there have been few studies that have examined the postprandial metabolism of unaltered folic acid, principally because of the difficulty of detecting it in the circulation thus ruling out studies of bioavailability and metabolic availability. One study (Johns et al. 1961) examined the metabolism of intravenously injected radiolabelled folic acid in man. However, their results cannot be compared with the response of folic acid administered orally where the bulk of the folate is converted to 5-methyltetrahydrofolate. Previously published studies include those conducted by Kelly et al. (1996) who examined the serum response to a large bolus dose of folic acid and Sweeney et al. (2003) who administered physiological doses to healthy volunteers. In both studies unmetabolised folic acid was detected in serum. 

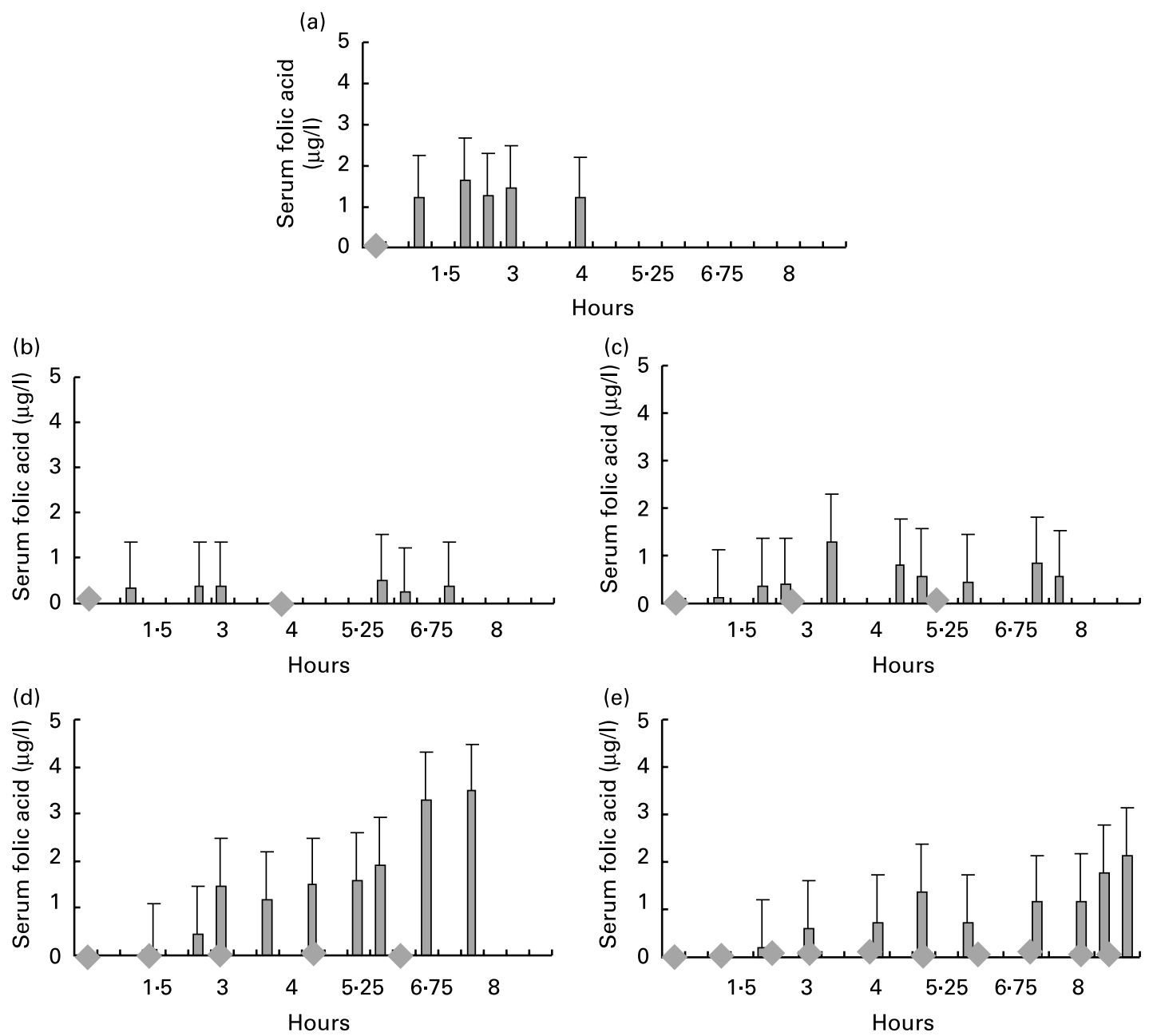

Fig. 6. Mean serum folic acid response of four subjects who consumed $1 \mathrm{mg}$ folic acid in fortified bread in five different dosage schedules in a series of intervention studies conducted 2 weeks apart. A total of $1 \mathrm{mg}$ was consumed in all dosage schedules. For details of procedures, see p. 146. The thin vertical boxs show the standard errors of the means. (a), Mean response after $1 \mathrm{mg}$ was consumed as a single dose in one slice of bread. (b), Mean response after $1 \mathrm{mg}$ was consumed in two equal doses of $500 \mu \mathrm{g}$ served $4 \mathrm{~h}$ apart. (c), Mean response after $1 \mathrm{mg}$ was consumed in three equal doses of $333 \mu \mathrm{g}$ served $4 \mathrm{~h}$ apart. (d), Mean response after $1 \mathrm{mg}$ was consumed in four equal doses of $200 \mu \mathrm{g}$ served $90 \mathrm{~min}$ apart. (e), Mean response after $1 \mathrm{mg}$ was consumed in ten equal doses of $100 \mu \mathrm{g}$ served $1 \mathrm{~h}$ apart. $\diamond$, Time-point for bread consumption.

In this paper we tested the effects of five regimens of folic acid totalling $1 \mathrm{mg}$ in fortified bread on serum folic acid response. These regimens consisted of a single bolus dose of $1 \mathrm{mg}$, two doses of $500 \mu \mathrm{g}$, three doses of $333 \mu \mathrm{g}$, five doses of $200 \mu \mathrm{g}$ and ten doses of $100 \mu \mathrm{g}$. Compliance was demonstrated by a significant total serum response in all individuals. We demonstrate the appearance of unaltered folic acid in the serum of all subjects at all of the test doses with an apparent accumulation of folic acid at regimens 4 and 5. A likely

Table 1. Serum folic acid assay performance

\begin{tabular}{|c|c|c|c|c|c|c|c|}
\hline \multirow[b]{2}{*}{ Serum } & \multicolumn{3}{|c|}{ Intra-assay } & \multicolumn{3}{|c|}{ Inter-assay } & \multirow[b]{2}{*}{$n$} \\
\hline & Mean & SD & $\mathrm{CV}(\%)$ & Mean & SD & $\mathrm{CV}(\%)$ & \\
\hline Endogenous & 0.00 & & & 0.00 & & & \\
\hline$+1 \mathrm{ng} / \mathrm{ml}$ & 1.026 & 0.08 & $7 \cdot 8$ & 0.998 & 0.09 & 9.02 & 8 \\
\hline$+3 \mathrm{ng} / \mathrm{ml}$ & 2.993 & 0.09 & 3.03 & 2.994 & 0.10 & $3 \cdot 34$ & 9 \\
\hline$+5 \mathrm{ng} / \mathrm{ml}$ & 5.031 & 0.12 & 2.42 & $5 \cdot 018$ & 0.15 & 2.99 & 8 \\
\hline
\end{tabular}

explanation for the cumulative effect seen in both of these studies is that the repeat doses of folic acid were given around the time of known $T_{\max }$ of approximately $2 \mathrm{~h}$ (Kelly et al. 1997) for folic acid in serum of the preceding slice. It is noteworthy that in these acute studies no presaturation with folic acid was given to any of the subjects. It is possible therefore that these findings under-represent what would have occurred if subjects had been pre-saturated, or indeed, if they were consuming these doses chronically, such as under a fortification programme. It has been demonstrated that fortification of the US food supply tends to increase folate intakes of consumers at the high end of the intake distribution curves in the general population to a greater extent than it affects consumers at the low end of the intake distribution curves in the target population (Crane et al. 1995).

However, because of the pilot nature of the study as well as large variability in response between individuals, sample size may have been too small to show statistical significance. A recent report (SW Bailey, MC Syslo and JE Ayling, unpublished results) demonstrated high variability in dihydrofolate 
reductase activity in man. This may explain the marked interindividual differences in responses to the regimens tested in our pilot studies.

We based these experiments on the minority of the general population at the high extremes of flour-based products, that is, those who were calculated to have folic acid intakes of $1 \mathrm{mg}$ and greater under the current US fortification regimen which was designed to deliver a mean of $100 \mu \mathrm{g}$. Recent calculations (Quinlivan \& Gregory, 2003) suggest that the actual amount consumed is $>210 \mu \mathrm{g} / \mathrm{d}$. Moreover, daily consumption patterns of 'snacking' or 'grazing' among teenagers, together with the reportedly high consumption of flour-based products among the elderly (Ministry of Agriculture Fisheries and Food and Department of Health, 1994) would suggest that regimens 3-5 would most closely resemble consumption in that section of the population who are high consumers of flour-based products. Our design for study 1 was based on the finding of Kelly et al. (1996) who demonstrated that with a $3 \mathrm{mg}$ bolus of folic acid the serum folic acid response peaked at $80 \mathrm{~min}$ and diminished towards baseline thereafter. We did not anticipate that $1 \mathrm{mg}$ folic acid would be present after $4 \mathrm{~h}$ therefore we did not collect samples after the $4 \mathrm{~h}$ period. In light of the interesting observations noted from the other studies, it is indeed a limitation of the study that these the serum samples from subjects in regimen 1 cannot be compared with the other regimens at the later time-points.

The substantial reduction in neural tube defects in the USA justifies the introduction of universal folic acid fortification. A need has been identified, however, to explore ways of improving folate intakes in targeted subgroups including females of childbearing age (Honein et al. 2001). While we cannot comment on the direct or indirect adverse implications of our results either in the short term or in the long term, what we can say is that synthetic folic acid was detected in all subjects at all test doses. In light of this, initiatives to increase such intake, particularly by increasing the fortification dosage, should be approached prudently.

\section{References}

Charles D, Ness AR, Campbell D, Smith GD \& Hall MH (2004) Taking folate in pregnancy and risk of maternal cancer. $\mathrm{Br}$ Med J 329, 1375-1376.
Committee on Medical Aspects of Food and Nutrition Policy (2000) Folic Acid and the Prevention of Disease. London: The Stationary Office.

Crane NT, Wilson DB, Cook DA, Lewis CJ, Yetley EA \& Rader JL (1995) Evaluating food fortification options, general principles revisited with folic acid. Am J Public Health 85, 660-666.

Fairfield KM \& Fletcher RH (2002) Vitamins for chronic disease prevention in adults: scientific review. JAMA 287, 3116-3126.

Food and Drug Administration (FDA) (1996) Food labeling: health claims and food label statements; folate and neural tube defects. Fed Reg 61, 44, 8752-8807.

Honein MA, Paulozzi LJ, Mathews TJ, Erickson JD \& Wong LY (2001) Impact of folic acid fortification of the US food supply on the occurrence of neural tube defects. JAMA 285, 2981-2986.

Johns DG, Sperti S \& Burgen AS (1961) The metabolism of tritiated folic acid in man. $J$ Clin Invest 40, 1684-1695.

Kelly P, McPartlin J \& Scott JM (1996) A combined high-performance liquid chromatographic microbiological assay for serum unmetabolised folic acid. Anal Biochem 238, 179-183.

Kelly P, McPartlin J, Goggins M, Weir DG \& Scott JM (1997) Unmetabolised folic acid in serum: acute studies in subjects consuming fortified food and supplements. Am J Clin Nutr 65, $1790-1795$.

Kim Y-I (2004) Will mandatory folic acid fortification prevent or promote cancer. Am J Clin Nutr 80, 1123-1128.

Ministry of Agriculture Fisheries and Food and Department of Health (1994) The Dietary and Nutritional Survey of Adults, pp. 39-46. London: H.M. Stationery Office.

Molloy A \& Scott JM (1997) Microbiological assay for serum, plasma and red cell folate using cryopreserved microtitre plate method. Methods Enzymol 281, 43-53.

National Academy of Sciences (1998) Dietary Reference Intakes for Thiamin, Riboflavin, Niacin, Vitamin B6, Folate, Vitamin B12, Pantothenic Acid, Biotin, and Choline. A Report of the Standing Committee on the Scientific Evaluation of Dietary Reference Intakes and its Panel on Folate, Other B Vitamins, and Choline and Subcommittee on Upper Reference Levels of Nutrients, Food and Nutrition Board, Institute of Medicine. http://books.nap.edu/ catalog/6015.html.

Quinlivan EP \& Gregory JF (2003) Effect of food fortification on folic acid intake in the United States. Am J Clin Nutr 77, $221-225$.

Savage DG \& Lindenbaum J (1995) Folate-cobalamin interactions. In Folates in Health and Disease, pp. 237-285 [LB Bailey, editor]. New York: Marcel Dekker.

Sweeney MR, McPartlin J, Weir DG \& Scott JM (2003) Measurements of subnanomolar concentrations of unmetabolised folic acid in serum. J Chromotogr B 788, 187-191. 